\title{
Bovine serum albumin-based nanoparticles containing the flavonoid rutin produced by nano spray drying
}

\author{
Regiellen Cristina Pedrozo¹, Emilli Antônio', Najeh Maissar Khalil', Rubiana Mara Mainardes ${ }^{\circledR *}$
}

${ }^{1}$ Laboratory of Pharmaceutical Nanotechnology, Universidade Estadual do Centro-Oeste, Guarapuava, PR, Brazil

\begin{abstract}
Rutin is a flavonoid compound obtained from different vegetables and fruits; specifically, it is found in the seeds of buckwheat and in fruit peels, particularly citrus. It is also an important constituent of red wine. Rutin exhibits various biological properties including antiviral, vasoprotective, anti-inflammatory, and anticarcinogenic activities. However, its antioxidant activity is the most well studied. Despite the potential for in vitro applications, rutin presents low oral bioavailability that affects its biological activities. Nanoparticles composed of polymers, protein, or lipids are of great importance in the pharmaceutical and nutraceutical areas due to their physicochemical properties, which improve the pharmacokinetics of the drug which is loaded within. This study presents the production of bovine serum albumin (BSA) nanoparticles containing rutin by nano spray drying. Nanoparticles were characterized in terms of mean particle size, size distribution, morphology, zeta potential, and drug content; as well as their antioxidant activity. The optimized spray-drying conditions produced spherical particles with a mean size of $316 \mathrm{~nm}$, zeta potential of $-32 \mathrm{mV}$, and encapsulation efficiency around $32 \%$. Moreover, when antioxidant activity toward the $\mathrm{ABTS}^{+}$radical was assayed, nanoencapsulation increased the $\mathrm{IC}_{50}$ of rutin by 2 -fold. The nano spray-drying process proved to be suitable for the production of rutin-loaded BSA nanoparticles with potential antioxidant activity.
\end{abstract}

Keywords: Nano spray drying. Rutin. Nanoparticles. Bovine serum albumin. Antioxidant.

\section{INTRODUCTION}

Rutin (3,3', 4',5,7-Pentahydroxyflavone 3 -rutinoside) is a naturally occurring flavonoid found in the floral buds of Sophora japonica L. and in buckwheat and fruit peels, especially those of citrus fruits (orange, grapefruit, lemon, and lime). This compound is also an important constituent of red wine. Rutin is well known for its significant antioxidant and other important pharmacological activities, including antiviral, vasoprotective, anti-inflammatory, and anticarcinogenic properties (Cheron et al., 2015; Li et al., 2014; MendesJunior et al., 2013; Kandemir et al., 2015).

However, rutin is poorly soluble in aqueous solutions, which results in limited bioavailability when administered orally and consequent reduced efficacy (Myiake et al., 2000). These drawbacks have limited the use of rutin in the pharmaceutical and food

\footnotetext{
*Correspondence: R. M. Mainardes. Laboratório de Nanotecnologia Farmacêutica, Universidade Estadual do Centro-Oeste. Rua Simeão Camargo Varela de Sá 03, CEP 85040-080 - Guarapuava, PR, Brazil. E-mail: rubianamainardes@hotmail.com
}

industries. Therefore, there is considerable interest in the development of strategies to improve the therapeutic efficacy of rutin, and the potential of nanotechnology for this purpose has been highlighted (Mauludin, Müller, Keck, 2009; Zhang, Han, 2018; Pandey et al., 2018; Ishak, Mostafa, Kamel, 2017). Nanoencapsulation of drugs and bioactive compounds with low solubility, volatility, or viscosity is an important tool to improve these characteristics and control the release profiles. In addition, nanoencapsulation can protect the molecule from premature degradation or loss of functionality, and improve the biopharmaceutical and pharmacokinetic properties, resulting in improved therapeutic efficacy (Ravindran et al., 2018; Yao, Mcclements, Xiao, 2015; Khan, Gurav, 2018; Amreddy et al., 2018).

Various nanoencapsulation techniques have been reported, including emulsification, nanoprecipitation, desolvation, and spray drying. Although it is often used for dehydration of samples, spray drying can be used as a method of encapsulation in order to trap active materials within an inert matrix (Tewa-Tagne, Briançon, Fessi, 2007). The technique of nano spray drying is a recently 
developed method of encapsulation that uses a vibrating mesh technology to produce high-quality particles of ultrafine size. The main advantage is that particle formation occurs in a single-step continuous and scalable process (Lee et al., 2011). However, there is little published information regarding the production of nanoparticles by nano spray drying (Li et al., 2010; Pápay et al., 2017; Tewa-Tagne, Briançon, Fessi, 2007).

Additionally, few studies report the use of natural polymers for nanoencapsulation of rutin (Ahmad et al., 2016; Konecsni, Low, Nickerson, 2012; Oliveira et al., 2016, Zhang, Han, 2018). Bovine serum albumin (BSA) is a non-toxic, biodegradable, and low-cost natural polymer with great potential as a carrier in food and pharmaceutical applications (Jahanshahi, Najafpour, Rahimnejad, 2008; Jun et al., 2011; Wang et al., 2016a). In this work, rutinloaded BSA nanoparticles were produced by nano spray drying, and their main characteristics evaluated. The free radical scavenging activity of the nanoparticles was also evaluated.

\section{MATERIAL AND METHODS}

\section{Reagents and material}

Rutin, bovine serum albumin (BSA), 2,2'-azinobis (3-ethylbenzothiazoline-6-sulfonic acid) diammonium salt (ABTS), potassium persulfate (dipotassium peroxydisulfate) and Tween ${ }^{\circledR} 80$ were obtained from Sigma-Aldrich (USA). Ethanol (99.8\%) was purchased from Vetec-QuímicaFina (Brazil), methanol was purchased from Merck ${ }^{\circledR}$ (Germany), phosphate buffered saline (PBS) pH 7.4 was obtained from Sigma-Aldrich. Water with a conductivity of $18 \mathrm{M} \Omega$ was purified using a Milli-Q Plus system (Millipore).

\section{Methods}

\section{Preparation of rutin-loaded bovine serum albumin nanoparticles}

Rutin-loaded nanoparticles were prepared by nano spray drying (Nano Spray-Dryer B-90; Buchi). Briefly, $5 \mathrm{mg}$ of rutin and $25 \mathrm{mg}$ of BSA were dissolved in $6.6 \mathrm{~mL}$ of ultrapure water, $3 \mathrm{~mL}$ of ethanol, and $0.4 \mathrm{~mL}$ of Tween ${ }^{\circledR}$ 80 . The solution was filtered $(0.45 \mu \mathrm{m})$ to minimize clogging of the mesh. Next, the sample was dried by spraying, with the following parameters: inlet temperature of $100{ }^{\circ} \mathrm{C}$, pressure of $35 \mathrm{mBar}$, nitrogen flow rate of $101 \mathrm{~L} / \mathrm{min}$ and mesh size of $4.0 \mu \mathrm{m}$. The dried powder was collected with the aid of a scraper, and stored until characterization.

\section{Particle size and polydispersity index analysis}

The particle size, size distribution, and polydispersity index (PDI) of nanoparticles were determined by dynamic light scattering (DLS) using a BIC 90Plus (Brookhaven Instruments Corp). Samples were diluted in ultrapure water and measurements were performed at a scattering angle of $90^{\circ}$ and temperature of $25^{\circ} \mathrm{C}$. All measurements were carried out in triplicate.

\section{Measurement of zeta potential}

Zeta potential was determined from the electrophoretic mobility by Laser Doppler Anemometry (ZetaSizer ZS, Malvern). Samples were diluted in $0.1 \mathrm{M}$ $\mathrm{KCl}$, placed in the electrophoretic cell, and a potential of $\pm 150 \mathrm{mV}$ was applied. Three measurements were carried out for each sample and the zeta potential was calculated.

\section{Determination of rutin encapsulation efficiency}

The amount of rutin encapsulated in the nanoparticles was determined directly using the solventextraction method, as follows. A known amount of dried nanoparticles was treated with methanol for the extraction of rutin by ultrasonication followed by centrifugation at $14,000 \mathrm{rpm}$ for $15 \mathrm{~min}$. The supernatant containing rutin was diluted with ethanol. The rutin content of the nanoparticles was calculated by measuring the absorbance of the diluted sample solution at $355 \mathrm{~nm}$ using a UVVisible spectrophotometer (UNICO-2100) and comparing to a standard calibration curve prepared with known concentrations of rutin in ethanol. The encapsulation efficiency (\%) was calculated using Eq. (1):

Encapsulation efficiency $(\%)=\frac{\text { amount of rutin determine }(\mathrm{mg})}{\text { amount of rutin added }(\mathrm{mg})} \times 100$

Analysis of morphology

Morphology of the nanoparticles was investigated using scanning electron microscopy (SEM; VEGA3, Tescan) at an accelerating voltage of $5.0 \mathrm{kV}$. Nanoparticles were coated with gold prior to imaging.

\section{Determination of scavenger activity}

The cationic ABTS radical is routinely used to assess the radical-scavenging abilities of flavonoids and phenolic agents. The ABTS assay used has been previously described by Re and collaborators, and modified by Kuskoski and collaborators (Kuskoski et al., 2004; Re et al., 1999). The $\mathrm{ABTS}^{+}$radical was produced by a chemical reaction between ABTS and potassium persulfate, which were mixed in a stoichiometric ratio of 1:0.5 and incubated in the dark at room temperature for $12 \mathrm{~h}$. The ABTS ${ }^{++}$solution was diluted in a $50 \mathrm{mM}$ 
phosphate buffer (PB) pH 7.4 until an absorbance of 0.70 (at $734 \mathrm{~nm}$ ) was reached. Different concentrations of free or nanoencapsulated rutin, ranging from $1-5 \mu \mathrm{g} / \mathrm{mL}$ were analyzed by incubation at $37{ }^{\circ} \mathrm{C}$ under constant agitation in the dark for $0,24,48$, or $72 \mathrm{~h}$. After incubation, aliquots with known concentrations were incubated for $30 \mathrm{~min}$ with $\mathrm{ABTS}^{+}$, and the absorbance was measured at $734 \mathrm{~nm}$. Plain PB was used as the negative control. The decrease in absorbance is proportional to the antioxidant effect of the test compound. The percentage of radical inhibition was therefore calculated according to Eq. (2):

$$
\% \text { Inhibition }=\frac{A c}{A t} \times 100
$$

where Ac is the absorbance of control and At is the absorbance of the unknown sample.

The $\mathrm{IC}_{50}$ (minimum concentration required to reduce the concentration of the $\mathrm{ABTS}^{+}$radical by $50 \%$ ) was determined by extrapolating the value of $\mathrm{x}$ when $y=50$ from the graph of percentage inhibition versus drug concentration.

\section{RESULTS AND DISCUSSION}

\section{Production and characterization of rutin-loaded BSA nanoparticles}

The Nanospray-Dryer B-90 used in this study is one of a new generation of spray dryers developed for nanoparticle formulation (Lee et al., 2011; Panda et al., 2016; Pérez-Masiá et al., 2015). The selection of the solvent or solvent mixtures was initially considered for the dissolution of both the polymer and drug. The solvent is a critical parameter of the process since it defines the inlet temperature and also affects the drug loading. Ethanol is a widely used solvent for the encapsulation of drugs by spray drying (Baba, Nishida, 2013; Kaewjan, Srichana, 2016; Son, Longest, Hindle, 2013). However, the present study utilized BSA as a carrier which, due to its hydrophilic nature, is poorly soluble in ethanol. In order to optimize the encapsulation of rutin, a mixture of ethanol and water was used, as rutin is soluble in ethanol. Tween ${ }^{\circledR} 80$, a nonionic surfactant, was included to reduce the surface tension and allow the passage of liquid through the apertures of the mesh. As previously reported, this resulted in the formation of smaller droplets compared with those produced without surfactant (Miller, Butler Ellis, 2000; Schmid, Arpagaus, Friess, 2011). Additionally, the surfactant may have the advantage of inhibiting protein aggregation (Kerwin et al., 1998; Wang, Wang, Wang, 2008) and producing a smooth particle surface after spray drying (Adler, Unger, Lee, 2000). Another parameter that can directly affect particle size is the mesh size. In general, the average particle size decreases with decreasing mesh size (Baba, Nishida, 2013; Lee et al., 2011; Panda et al., 2016). Therefore, a mesh with an aperture size of $4 \mu \mathrm{m}$ was chosen.

Several assays were performed to evaluate the formation of the rutin-loaded BSA nanoparticles using the nano spray-drying technique, with various ratios of solvents, inlet temperatures, and feed rates. The best results were obtained using a water:ethanol:surfactant mixture $(1: 0.45: 0.06, \mathrm{v} / \mathrm{v} / \mathrm{v})$ and inlet temperature of $100{ }^{\circ} \mathrm{C}$. These conditions produced batches of nanoparticles with reproducible particle characteristics. The main characteristics of the nanoparticles are shown in Table I.

The nanoparticles presented a mean diameter of about $300 \mathrm{~nm}$, which is considered adequate for prolonged delivery of drugs administered by different routes, including the parenteral route (Liu et al., 2010; Oliveira et al., 2017). However, a high standard deviation was observed, indicating a relatively broad size distribution. Lee and collaborators (2011) used nano spray drying with a $4 \mu \mathrm{m}$ spray mesh to produce BSA nanoparticles with a mean size of $460 \mathrm{~nm}$. The PDI of rutin-loaded BSA nanoparticles in our study indicated a monodisperse system, with values ranging from 0-0.3 Homogeneous samples have a PDI close to 0 and polydisperse samples are close to 1 . A monodisperse system is desirable because it contains only one population in regards to size, which plays an important role in tissue accumulation and renal clearance (Alexis et al., 2008; Wang et al., 2016b). The size distribution profile of the rutin-loaded BSA nanoparticles is illustrated in Figure 1, revealing a monomodal profile; however, the distribution was relatively broad. The mean size and size distribution of nanoparticles are the most important characteristics which influence the in vivo distribution. Many studies have demonstrated the significant advantages that nanoparticles offer over microparticles, due to their reduced size (Panyam, Labhasetwar, 2003; Singh, Lillard, 2009).

TABLE I - Mean diameter, polydispersity index, zeta potential and encapsulation efficiency of BSA nanoparticles containing rutin

\begin{tabular}{cccc}
\hline Mean size (nm) & Polydispersity index & Zeta potential $(\mathbf{m V})$ & Encapsulation efficiency (\%) \\
\hline $316 \pm 210$ & $0.27 \pm 0.11$ & $-32.1 \pm 2.6$ & $32 \pm 9$ \\
\hline
\end{tabular}


Visual examination of SEM images indicated that the particles were spherical in shape; however, some aggregation was observed (Figure 2). The size measurements from SEM were comparable with those of DLS analysis, indicating that the particle diameters were about 200-600 nm. Pérez-Masiá et al. (2015) compared folic acid-loaded nanoparticles produced using either nano spray drying or electrospraying. The authors observed nano spray-dried particles to have higher mean sizes and a broader size distribution, which was suggested to be due to the difficulty in controlling the particle size and morphology using this technology.

The zeta potential of nanoparticles greatly influences their stability in suspension as it controls the electrostatic repulsion between the particles. A colloidal system with a zeta potential value greater than $\pm 30 \mathrm{mV}$ is considered a stable formulation, since particles will repel each other (Clogston, Patri, 2011). In this work, the zeta potential of the rutin-loaded BSA nanoparticles was more negative than $-30 \mathrm{mV}$. This negativity is due to the terminal groups of BSA, and the positioning of these groups on the surfaces of the nanoparticles. This may produce a high energy barrier which stabilizes the formulation and prevents aggregations of the particles. The surface charge also influences the cellular uptake and intracellular distribution of the nanoparticles. It is suggested that negatively-charged particles bind to cationic sites in the form of clusters. In addition, nanoparticles which are already attached to the cell surface have a reduced charge density, which may favor the adsorption of other free particles (Patil et al., 2007; Wilhelm et al., 2003). The studies of Limbach and collaborators (2005) using human lung fibroblast cells also indicated that these cells rapidly absorb negativelycharged oxide nanoparticles.

Although BSA is hydrophilic, its structure is very flexible and the molecule has several binding sites throughout its structure. These characteristics mean that many compounds with different structures and solubilities are able to bind BSA (Fang et al., 2011). Hydrophobic molecules are preferentially adsorbed at the tryptophan residues of BSA, therefore promoting the formation of a hydrophobic core surrounded by a hydrophilic outer layer (Fang et al., 2011). However, rutin is hydrophobic. The low encapsulation efficiency that we observed may be due to two factors: i) the low affinity of BSA to rutin, or ii) the degradation of rutin during spray drying due to the high temperatures involved. According to Buchner et al. (2006), flavonoids such as quercetin and rutin undergo degradation upon heating to $100{ }^{\circ} \mathrm{C}$ in aqueous solution. This could explain the low incorporation of rutin into the nanoparticles. Pérez-Masiá et al. (2015) also reported that the high temperatures applied in the nano spray dryer eliminate water from polymeric/biopolymeric solutions, and influence the stability of bioactive compounds.

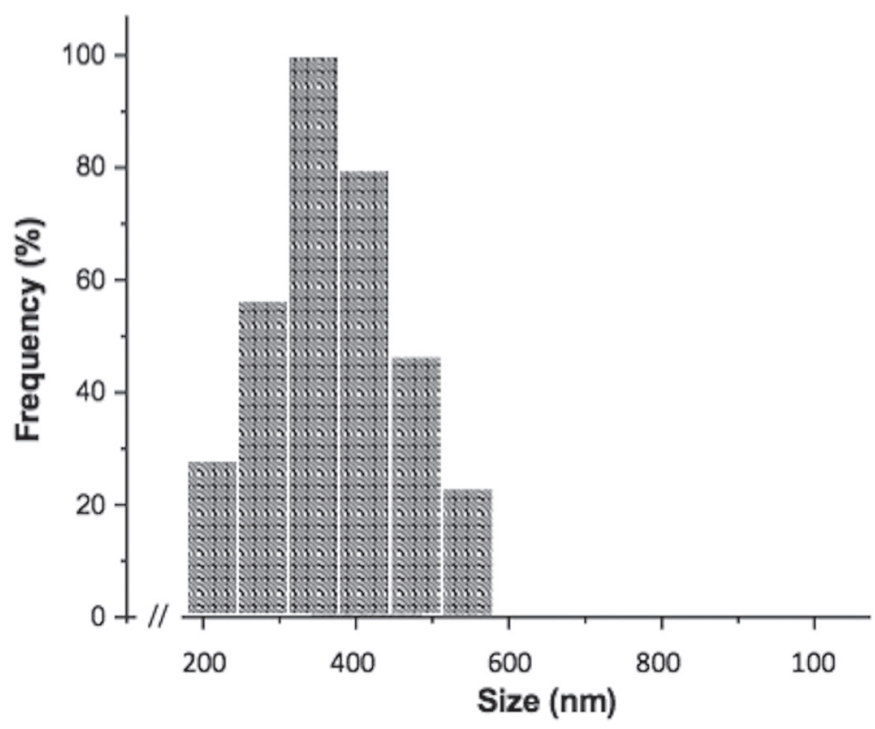

FIGURE 1 - Size distribution profile of BSA nanoparticles containing rutin.

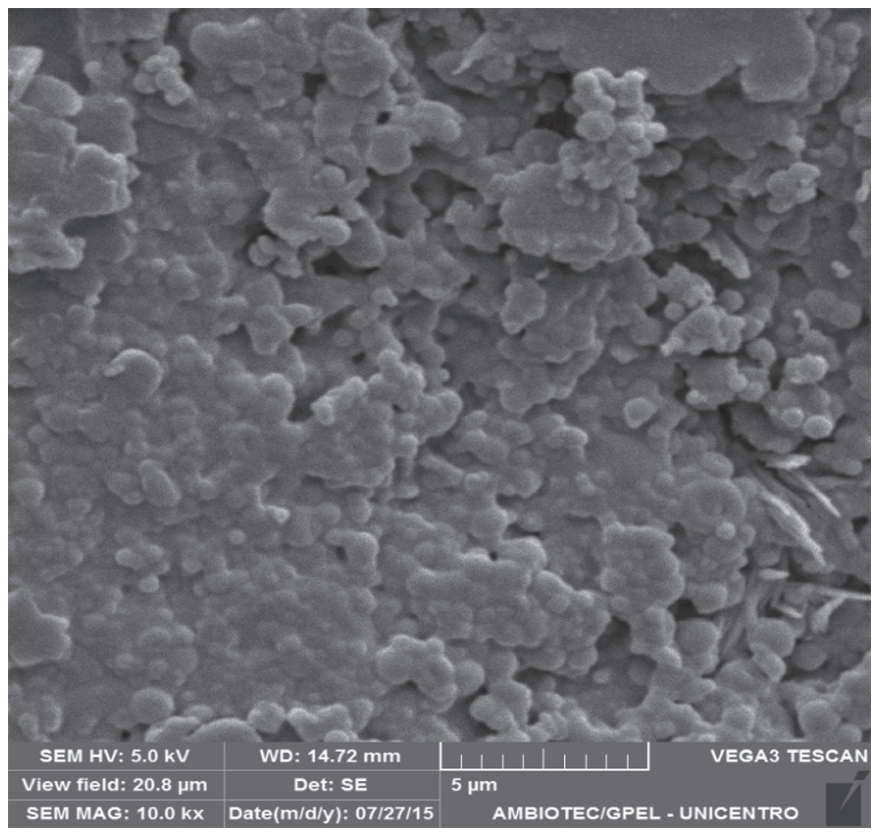

FIGURE 2 - SEM image of BSA nanoparticles containing rutin with increase of $10 \mathrm{kx}$.

\section{Radical scavenging activity}

The ABTS radical cation decolorization assay is widely used for the assessment of the radical scavenging activity of various substances. Rutin-loaded BSA nanoparticles were evaluated for their ability to scavenge $\mathrm{ABTS}^{+}$, to assess whether nanoencapsulation influences 
the antioxidant activity of rutin. The results of radical scavenging of free and nanoencapsulated rutin at different concentrations and times are presented in Table II.

TABLE II - Percentage of radical ABTS + +inhibition by rutin (free and nanostructured) in sodium phosphate buffer $(50 \mathrm{mM}$, $\mathrm{pH} 7.4)$, in the absence of light at room temperature $(\chi=734 \mathrm{~nm})$

\begin{tabular}{|c|c|c|}
\hline $\begin{array}{l}\text { Concentration } \\
(\mu \mathrm{g} / \mathrm{mL})\end{array}$ & Free Rutin (\%) & $\begin{array}{l}\text { Rutin-loaded BSA } \\
\text { nanoparticles (\%) }\end{array}$ \\
\hline \multicolumn{3}{|c|}{$\mathbf{O h}$} \\
\hline 1.0 & $31.0 \pm 4.1$ & - \\
\hline 2.0 & $58.6 \pm 13.7^{\mathrm{a}}$ & $16.7 \pm 4.6^{\mathrm{b}}$ \\
\hline 3.0 & $89.5 \pm 1.5^{\mathrm{a}}$ & $29.4 \pm 1.7^{b}$ \\
\hline 4.0 & $95.3 \pm 4.0^{\mathrm{a}}$ & $44.2 \pm 5.1^{b}$ \\
\hline 5.0 & $98.8 \pm 0.1^{\mathrm{a}}$ & $55.4 \pm 2.2^{b}$ \\
\hline \multicolumn{3}{|c|}{$24 \mathrm{~h}$} \\
\hline 1.0 & $18.3 \pm 0.9^{\mathrm{a}}$ & $6.5 \pm 0.9^{b}$ \\
\hline 2.0 & $37.0 \pm 1.9^{\mathrm{a}}$ & $17.0 \pm 1.2^{b}$ \\
\hline 3.0 & $52.7 \pm 0.9^{\mathrm{a}}$ & $22.8 \pm 1.5^{b}$ \\
\hline 4.0 & $67.7 \pm 2.4^{\mathrm{a}}$ & $30.8 \pm 1.2^{b}$ \\
\hline 5.0 & $86.9 \pm 4.7^{\mathrm{a}}$ & $35.2 \pm 0.4^{b}$ \\
\hline \multicolumn{3}{|c|}{$48 \mathrm{~h}$} \\
\hline 1.0 & $27.7 \pm 0.7^{\mathrm{a}}$ & $11.4 \pm 5.3^{b}$ \\
\hline 2.0 & $53.8 \pm 2.2^{\mathrm{a}}$ & $22.3 \pm 1.2^{b}$ \\
\hline 3.0 & $67.6 \pm 3.6^{\mathrm{a}}$ & $31.2 \pm 3.5^{b}$ \\
\hline 4.0 & $84.3 \pm 3.5^{\mathrm{a}}$ & $44.6 \pm 2.6^{b}$ \\
\hline 5.0 & $98.8 \pm 0.6^{\mathrm{a}}$ & $54.6 \pm 2.9^{b}$ \\
\hline \multicolumn{3}{|c|}{$72 \mathrm{~h}$} \\
\hline 1.0 & $30.7 \pm 0.8^{\mathrm{a}}$ & $10.9 \pm 0.9^{b}$ \\
\hline 2.0 & $56.9 \pm 3.4^{\mathrm{a}}$ & $26.9 \pm 0.8^{b}$ \\
\hline 3.0 & $72.5 \pm 4.1^{\mathrm{a}}$ & $38.2 \pm 3.1^{b}$ \\
\hline 4.0 & $86.9 \pm 1.8^{\mathrm{a}}$ & $51.6 \pm 1.3^{b}$ \\
\hline 5.0 & $99.5 \pm 0.3^{\mathrm{a}}$ & $57.6 \pm 5.8^{b}$ \\
\hline
\end{tabular}

a, b Percentage of inhibition of radical ABTS + \pm standard deviation per line analyzed. Same letters mean statistical equality and inequality statistics are shown for different letters (Student's t test and $\alpha 0.05)(n=3)$.

Free rutin showed a concentration-dependent scavenging activity, with increased rutin concentrations resulting in improved antioxidant activity. Small fluctuations in the antioxidant profile of free rutin were observed along the time course of the assay $(72 \mathrm{~h})$, indicating the stability of molecule in the medium. Rutin-loaded BSA nanoparticles also demonstrated a concentration-dependent profile, although the intensity of response was reduced compared with free rutin at all incubation times and concentrations $(\mathrm{p}<0.05)$. Over time, some fluctuations in the percentages of radical scavenging were observed, and after $72 \mathrm{~h}$ the nanoparticles exhibited increased antioxidant potential when compared with previous times, reaching a calculated radical inhibition of $58 \%$. This observation may be associated with the slow and sustained release profile of rutin from BSA nanoparticles (Antonio, Khalil, Mainardes, 2016; Fonseca, Khalil, Mainardes, 2017).

The $\mathrm{IC}_{50}$ is an important parameter for quantitative evaluation of the in vitro effects of drugs. In the scavenging assay, this value represents the drug concentration required to inhibit $50 \%$ of the radical at a particular time. The results are presented in Table III. The $\mathrm{IC}_{50}$ values for free rutin presented few variations over time, and were about 2 -fold lower than those of rutin-loaded BSA nanoparticles throughout the experiment $(\mathrm{p}<0.05)$.

TABLE III - $\mathrm{IC}_{50}$ of rutin (free and nanostructured), over the capture of the ABTS + cation radical in sodium phosphate buffer $(50 \mathrm{mM} . \mathrm{pH} 7.4)$ in the absence of light at room temperature $(\chi=734 \mathrm{~nm})$

\begin{tabular}{lcc}
\hline Time (h) & $\begin{array}{c}\mathbf{I C}_{\mathbf{5 0}} \text { of free rutin } \\
(\boldsymbol{\mu g} / \mathbf{m L})\end{array}$ & $\begin{array}{c}\mathbf{I C}_{\mathbf{5 0}} \text { of rutin-loaded BSA } \\
\text { nanoparticles }(\boldsymbol{\mu g} / \mathbf{m L})\end{array}$ \\
\hline 0 & $2.0 \pm 0.1^{\mathrm{a}}$ & $4.55 \pm 0.2^{\mathrm{b}}$ \\
24 & $2.8 \pm 0.06^{\mathrm{a}}$ & $7.06 \pm 0.2^{\mathrm{b}}$ \\
48 & $2.15 \pm 0.05^{\mathrm{a}}$ & $4.52 \pm 0.4^{\mathrm{b}}$ \\
72 & $2.07 \pm 0.04^{\mathrm{a}}$ & $4.07 \pm 0.3^{\mathrm{b}}$ \\
\hline
\end{tabular}

${ }_{\mathrm{a}, \mathrm{b}}$ Mean of triplicate \pm standard deviation per line analyzed. Same letters mean statistical equality and inequality statistics are shown for different letters (Student's t test and $\alpha 0.05)(n=3)$.

Because of their size, nanoparticles offer a promising approach for improving the bioavailability of numerous pharmaceutical and nutraceutical compounds, especially poorly soluble substances such as functional lipids and natural antioxidants. They may prolong the residence time of the compound in the gastrointestinal tract by decreasing the influence of intestinal clearance mechanisms and increasing the available surface area for interaction with biological supports (Nair et al., 2010; Kawashima, 2001; Sgorla et al., 2018). They can also penetrate deeply into tissues via the fine capillaries and be efficiently absorbed by cells (Lamprecht et al., 2004), thus enabling the effective delivery of active compounds to target sites within the body. Although the present study revealed rutin-loaded nanoparticles presented lower free radical scavenging activity than the free compound, the cumulative effect of continuous drug release from nanoparticles, coupled with the pharmacokinetic advantages of nanoparticles, make 
the performance of drug-loaded nanoparticles higher than free drugs when administered in vivo. The antioxidant potential of rutin could therefore be exploited for the prevention and/or treatment of diseases in which oxidative stress is involved.

\section{CONCLUSION}

This study demonstrated the production of BSA nanoparticles containing the polyphenol rutin, using a new methodology of spray drying. This method resulted in the formation of nanoparticles with spherical morphologies, nanometric sizes, and negative zeta potential as well as a satisfactory amount of encapsulated drug. Results of antioxidant assays indicated a concentration-dependent profile for the free radical inhibition by both free and nanoencapsulated rutin. $\mathrm{The} \mathrm{IC}_{50}$ of rutin from nanoparticles was 2-fold higher than that of free rutin. Finally, the results confirm that the rutin-loaded BSA nanoparticles have adequate physicochemical characteristics for the delivery of rutin within the body.

\section{CONFLICTS OF INTEREST} interest.

The authors declare that they have no conflicts of

\section{ACKNOWLEDGMENT}

This research was supported by $\mathrm{CNPq}$ (Conselho Nacional de Desenvolvimento Científico e Tecnológico - Brazil) and FINEP (Financiadora de Estudos no País Brazil).

\section{REFERENCES}

Adler M, Unger M, Lee G. Surface composition of spray-dried particles of bovine serum albumin/trehalose/surfactant. Pharm Res. 2000;17(7):863-870.

Ahmad N, Ahmad R, Naqvi AA, Alam MA, Ashafaq M, Samim M6, Iqbal Z, Ahmad FJ. Rutin-encapsulated chitosan nanoparticles targeted to the brain in the treatment of cerebral ischemia. Int J Biol Macromol. 2016;91:640-55.

Amreddy N, Babu A, Muralidharan R, Panneerselvam J, Srivastava A, Ahmed R, Mehta M, Munshi A, Ramesh R. Recent advances in nanoparticle-based cancer drug and gene delivery. Adv Cancer Res. 2018;137:115-170.
Alexis F, Pridgen E, Molnar LK, Farokhzad OC.Factors affecting the clearance and biodistribution of polymeric nanoparticles. Mol Pharm. 2008;5(4):505-515.

Antonio E, Khalil NM, Mainardes RM. Bovine serum albumin nanoparticles containing quercetin: characterization and antioxidant activity. J Nanosci Nanotechnol. 2016;16(2)13461353.

Baba K, Nishida K. Steroid nanocrystals prepared using the nano spray dryer B-90. Pharmaceutics. 2013;5(1):107-114.

Buchner N, Krumbein A, Rohn S, Kroh L. Effect of thermal processing on the flavonols rutin and quercetin. Rapid Commun Mass Spectrom. 2006; 20:3229-3235.

Cheron N, Yu C, Kolawole AO, Shakhnovich EI, Wobus CE. Repurposing of rutin for the inhibition of norovirus replication. Arch Virol. 2015;160(9):2353-2358.

Clogston JD, Patri AK. Zeta potential measurement. Methods Mol Biol. 2011;697:63-70.

Fang R, Jing H, Chai Z, Zhao G, Stoll S, Ren F, et al. Study of the physicochemical properties of the BSA: Flavonoid nanoparticle. Eur Food Res Technol. 2011;233(2):275-283.

Fonseca DP, Khalil NM, Mainardes RM. Bovine serum albuminbased nanoparticles containing resveratrol: Characterization and antioxidant activity. J Drug Deliv Sci Technol. 2017;39:147-155.

Ishak Rah, Mostafa NM, Kamel AO. Stealth lipid polymer hybrid nanoparticles loaded with rutin for effective brain delivery - comparative study with the gold standard (Tween 80): optimization, characterization and biodistribution. Drug Deliv. 2017;24(1):1874-1890.

Jahanshahi M, Najafpour G, Rahimnejad M. Applying the Taguchi method for optimized fabrication of bovine serum albumin (BSA) nanoparticles as drug delivery vehicles. Afr J Biotechnol. 2008;7(4):362-367.

Jun JY, Nguyen HH, Paik SYR, Chun HS, Kang BC, Ko S. Preparation of size-controlled bovine serum albumin (BSA) nanoparticles by a modified desolvation method. Food Chem. 2011;127(4):1892-1898.

Khan T, Gurav P. PhytoNanotechnology: enhancing delivery of plant based anti-cancer drugs. Front Pharmacol. 2018;8:1002. 
Kaewjan K, Srichana T. Nano spray-dried pyrazinamide-Lleucinedry powders, physical properties and feasibility used as dry powder aerosols. Pharm Dev Technol. 2016;21(1):68-75.

Kandemir F, Ozkaraca M, Yildirim BA, Hanedan B, Kirbas A, Kilic K. Rutin attenuates gentamicin-induced renal damage by reducing oxidative stress, inflammation, apoptosis, and autophagy in rats. J Renal Fail. 2015;37(3):518-525.

Kawashima Y. Nanoparticulate systems for improved drug delivery. Adv Drug Deliv Rev. 2001;47(1):1-2.

Kerwin BA, Heller MC, Levin SH, Randolph, T.W. Effects of tween 80 and sucrose on acute short-term stability and long-term storage at $-20^{\circ} \mathrm{C}$ of a recombinant hemoglobin. J Pharm Sci. 1998;87(9):1062-1068.

Konecsni K, Low NH, Nickerson MT. Chitosan-tripolyphosphate submicron particles as the carrier of entrapped rutin. Food Chem. 2012;134(4):1775-1779.

Kuskoski E, Asuero AG, García-Parilla MC, Troncoso AM, Fett R. Actividad antioxidante de pigmentos antociánicos. Food Sci Technol. 2004;24(4):691-693.

Lamprecht A, Saumet JL, Roux J, Benoit JP.Lipid nanocarriers as drug delivery system for ibuprofen in pain treatment. Int J Pharm. 2004;278(2):407-414.

Lee, SH, Heng D, Ng WK, Chan HK, Tan RB. Nano spray drying: A novel method for preparing protein nanoparticles for protein therapy. Int J Pharm. 2011;403(1-2):192-200.

Li Q, Qiu Y, Mao M, Lv J. Zhang L, Li S, et al. Antioxidant mechanism of rutin on hypoxia-induced pulmonary arterial cell proliferation. Molecules. 2014;19(11):19036-19049.

Li X, Anton N, Arpagaus C, Belleteix F, Vandamme TF. Nanoparticles by spray drying using innovative new technology: The Büchi Nano Spray Dryer B-90. J Control Release. 2010;147(2):304-310.

LimbachLK, LiY, Grass RN, BrunnerTJ, Hintermann MA, Gunther $\mathrm{D}$, et al. Oxide nanoparticle uptake in human lung fibroblasts: effects of particle size, agglomeration, and diffusion at low concentrations. Environ Sci Technol. 2005;39(23): 9370-9376.

Liu D, Wang L, Liu Z, Zhang G, Zhang N. Preparation, characterization, and in vitro evaluation of docetaxel-loaded poly(lactic acid)-poly(ethylene glycol) nanoparticles for parenteral drug delivery. J Biomed Nanotechnol. 2010;6(6):675-682.
Mauludin R, Müller RH, Keck CM. Development of an oral rutin nanocrystal formulation. Int J Pharm. 2009;370(1-2):202-209.

Mendes-Junior LD, Monteiro MM, Carvalho AS, De Queiroz TM, Braga VA.Oral supplementation with the rutin improves cardiovagal baroreflex sensitivity and vascular reactivity in hypertensive rats. Appl Physiol Nutr Metab. 2013;38(11):10991106.

Miller PCH, Butler Ellis MC,Effects of formulation on spray nozzle performance for applications from ground-based boom sprayers. Crop Protection. 2000;19(8-10):609-615.

Miyake K, Arima H, Hirayama F, Yamamoto M, Horikawa T, Sumiyoshi H, Noda S, Uekama K. Improvement of solubility and oral bioavailability of rutin by complexation with 2-hydroxypropyl-beta-cyclodextrin. Pharm Dev Technol. 2000;5(3):399-407.

Nair HB, Sung B, Yadav VR, Kannappan R, Chaturvedi MM, Aggarwal BB. Delivery of antiinflammatory nutraceuticals by nanoparticles for the prevention and treatment of cancer. Biochem Pharmacol. 2010;80(12):1833-1843.

Oliveira CL, Veiga F, Varela C, Roleira F, Tavares E, Silveira I, et al. Characterization of polymeric nanoparticles for intravenous delivery: Focus on stability. Colloids Surf B Biointerfaces. 2017;150:326-333.

Oliveira, CA, Peres DD, Graziola F, Chacra NA, Araujo GL, Flórido AC, et al. Cutaneous biocompatible rutin-loaded gelatinbased nanoparticles increase the SPF of the association of UVA and UVB filters. Eur J Pharm Sci. 2016;81:1-9.

Panda A, Meena J, Katara R, Majumdar DK.Formulation and characterization of clozapine and risperidone co-entrapped spray-dried PLGA nanoparticles. Pharm Dev Technol. 2016;21(1):43-53.

Pandey P, Rahman M, Bhatt PC, Beg S, Paul B, Hafeez A, Al-Abbasi FA, Nadeem MS, Baothman O, Anwar F, Kumar $\mathrm{V}$. Implication of nano-antioxidant therapy for treatment of hepatocellular carcinoma using PLGA nanoparticles of rutin. Nanomedicine (Lond). 2018;13(8):849-70.

Panyam J, Labhasetwar V. Biodegradable nanoparticles for drug and gene delivery to cells and tissue. Adv Drug Deliv Rev. 2003;55(3):329-347. 
Pápay ZE, Kósa A, Boddi B, Merchant Z, Saleem IY, Zariwala MG, et al. Study on the Pulmonary Delivery System of Apigenin-Loaded Albumin Nanocarriers with Antioxidant Activity. J Aerosol Med Pulm Drug Deliv. 2017;30(4):1-15.

Patil S, Sandberg A, Heckert E, Self W, Seal S. Protein adsorption and cellular uptake of cerium oxide nanoparticles as a function of zeta potential. Biomaterials. 2007;28(31):4600-4607.

Pérez-Masiá R, Lopez-Nicolas R, Periago MJ, Ros R, Lagaron JM, Lopez-Rubio A. Encapsulation of folic acid in food hydrocolloids through nanospray drying and electrospraying for nutraceutical applications. Food Chem. 2015;168:124-133.

Ravindran S, Suthar JK, Rokade R, Deshpande P, Singh P, Pratinidhi A, Khambadkhar R, Utekar S. Pharmacokinetics, metabolism, distribution and permeability of nanomedicine. Curr Drug Metab. 2018;19(4):327-34.

Re R, Pellegrini N, Proteggente A, Pannala A, Yang M, RiceEvans C. Antioxidant activity applying an improved ABTS radical cation decolorization assay. Free Radic Biol Med. 1999;26(9):1231-1237.

Schmid K, Arpagaus C, Friess W. Evaluation of the Nano Spray Dryer B-90 for pharmaceutical applications. Pharm Dev Technol. 2011;16(4):287-294.

Sgorla D, Lechanteur A, Almeida A, Sousa F, Melo E, Bunhak É, Mainardes R, Khalil N, Cavalcanti O, Sarmento B. Development and characterization of lipid-polymeric nanoparticles for oral insulin delivery. Expert Opin Drug Deliv. 2018;15(3):213-222.

Singh R, Lillard JW. Nanoparticle-based targeted drug delivery. Exp Mol Pathol. 2009;86(3):215-223.
Son YJ, Longest PW, Hindle, M. Aerosolization characteristics of dry powder inhaler formulations for the excipient enhanced growth (EEG) application: Effect of spray drying process conditions on aerosol performance. Int J Pharm. 2013;443(12):137-145.

Tewa-Tagne P, Briançon S, Fessi H. Preparation of redispersible dry nanocapsules by means of spray-drying: Development and characterisation. Eur J Pharm Sci. 2007;30(2):124-135.

Yao M, McClements JD, Xiao H. Improving oral bioavailability of nutraceuticals by engineered nanoparticle-based delivery systems. Cur Opinion Food Sci 2015;2:14-19.

Wang C, Liu Z, Xu G, Yin B, Yao P. BSA-dextran emulsion for protection and oral delivery of curcumin. Food Hydrocoll. 2016a;61:11-19.

Wang T, Hu Q, Zhou M, Xia Y, Nieh MP, Lui Y. Development of "All natural" layer-by-layer redispersible solid lipid nanoparticles by nano spray drying technology. Eur J Pharm Biopharm. 2016b;107:273-285.

Wang W, Wang YJ, Wang DQ. Dual effects of Tween 80 on protein stability. Int J Pharm. 2008;347(1-2):31-38.

Wilhelm C, Billotey C, Roger J, Pons JN, Bacri JC, Gazeau F. Intracellular uptake of anionic superparamagnetic nanoparticles as a function of their surface coating. Biomaterials. 2003;24(6):1001-1011.

Zhang S, Han Y. Preparation, characterisation and antioxidant activities of rutin-loaded zein-sodium caseinate nanoparticles. PLoS One. 2018;13(3):e0194951.

Received for publication on $03^{\text {rd }}$ November 2017 Accepted for publication on $23^{\text {rd }}$ August 2018 